\title{
Reflection on Building a Long-term Mechanism to Promote Employment of University Graduates
}

\author{
Yu Yan* \\ School of Public Management Jilin University of Finance and Economics Changchun, Jilin Province, China \\ yanyu799@163.com
}

\begin{abstract}
Due to such reasons as the economic structure, educational system, social development, etc., university graduates are encountered with increasingly severe employment situations and the difficulty in getting university graduates is becoming more and more noticeable with each passing day. This calls for dynamic adjustment mechanisms in the building of disciplinary curriculums and talent cultivation, the building of the mechanism to foster the employment market, improving the employment guidance system, and improving the sectoral coordination mechanisms to transform university students' concepts on employment, improve university graduates' employment mechanisms, and innovating the higher education system.

Index Terms: university graduates, employment, long-term mechanism
\end{abstract}

\section{Connotation and Social Significance of University Graduates' Employment}

\section{A . University graduates' employment and rational allocation of human resources}

What is the "employment of university graduates"? The question refers to how to reasonable define the concept of "employment of university graduates". Whether the concept of "employment of university graduates" can be reasonably defined is directly related to the reasonable judgment of university graduates' employment situation and reasonable grasp of university graduates' employment level. Now the term of "employment of university graduates" usually refers to the full employment of college graduates, namely, full employment of college graduates as a type of human resources. Such employment can avoid the two-way idleness of talents and jobs, which, in volume terms, can reach the equilibrium of talent demand and supply to make the best use of human resources, and it can achieve reasonable allocations of the supply of talents in all sectors and across regions in terms of quality to narrow the development gap between regions and achieve common prosperity. The relevant departments should work together and make rational development and utilization of resources of university graduates to match up university graduates with employers in number, in quantity and in other aspects.

\section{$B$. Social significance of the employment of university graduates}

Since the reform and opening up, China has successively put forward the strategies of "rejuvenating the country through science and education" and "strengthening the country through talents", elevating personnel training up to an important position in the social construction. Nevertheless, with the gradual deepening of social construction, the traditional economic structure can no longer meet the long-term social development requirements. Although the state has been gradually engaged in active structural reforms to adapt to the needs of the actual situation in, the corresponding education institutional reform has fallen relatively behind. The university graduates cultivated with the traditional way lack competitiveness and sense of independent innovation. In addition, some universities simply pursue economic benefits by means of blind enrollment expansion, which has led to the decline in the quality of university graduates and further exacerbated the employment difficulty. How to improve the employment of university graduates and promote the employment of university graduates in a scientific manner is a big event related to social stability and long-term development of the socialist China, and it is worth the joint efforts from all walks of life of the whole society.

\section{II . Status Quo of Difficulty in Employment of University Graduates}

At this stage, due to the reasons in the education system, economic structure, social development, etc. college graduates are faced with an increasingly serious employment situation, which is exacerbated by the financial crisis that has increased the fierce competition in the employment.

\section{A . The blind expansion of university enrollment has led to a surge in the number of college students}

The intention of university enrollment expansion is indeed good, which is aimed at improving the level of education and scientific and cultural qualities of all the people, but the placement of these additionally-enrolled college graduates is by no means a small challenge. The nature of the problem is not simply the oversupply in that the gross enrollment rate of Chinese universities is merely $21 \%$, which, compared with the $30 \%$ of the Western countries, is still some distance, so the oversupply due to a variety of complex reasons is only an emerging superficial phenomenon, and the deeper reasons are worthy of our deep contemplation.

\footnotetext{
* I would like to thanks Youth Academic Talent Projects of Jilin University of Finance and Economics for their financial support.
} 


\section{$B$. The employment rate of university graduates is decreasing year by year.}

Through the comparison and analysis of the national employment data over the recent years, it is not difficult to see that, in terms of the employment rate of university graduates in recent years, the employment rate of the post-graduates is the highest, followed by the junior college graduates, and that of the undergraduates is the lowest. The overall employment rate is only around $80 \%$. That is to say, out of 100 graduates, about 20 people cannot find work.

\section{Mismatch of the market demand and the human resources of university graduates}

From the perspective of university students, some expertises are divorced from the market demand. The abilities and skills acquired find it hard to meet the needs of the market, resulting in a very easy elimination by the market; in terms of the market, the enterprises in the marketplace have some stereotyped distrust of the group of college graduates, which has also lowered the status of university graduates in society and gradually pushed them in the direction of the vulnerable groups.

\section{Unreasonable self positioning of university graduates}

Even after receiving education for more than a decade, university graduates are short of a rational perception of themselves and society. With their traditional concept on employment being deeply-rooted, they tend to indulge themselves in one-sided pursuit of huge cities, large enterprises and high wages, rather than get down to the grassroots and remote areas. The lack of a reasonable positioning on their own coupled with poor practical abilities disable these university graduates to find satisfying jobs and make the employment problem more detectable.

\section{III . Building a Long-term Mechanism to Promote the Employment of University Graduates}

A. Building a dynamically-adjusting mechanism of
disciplinary curriculum and talent training

With the constant change in the economic landscape, continuous development of society, relatively backward education reforms, and daily transformation of the structure of social demands for talent, it has become an irresistible trend to gradually set up a set of dynamically-adjusting mechanism for sound disciplinary curriculums and personnel training. The departments concerned should organize professional, stable and long-term personnel teams to make in-depth analyses of the current social situations, the employment situations and relevant impacting factors to obtain employment profiles for the coming period. Colleges and universities should take the opportunity to adjust their disciplinary setup structures and personnel training modes so that the trained graduates will become the talents needed by society. At the current stage, it is an important direction in talent raining to university graduates to work at the grassroots level or in west China, which is an irresistible trend in line with the needs of the Party and the state for social development. Due to China's specific national conditions, there is noticeable imbalanced regional development in China. However, as the economy continues to develop, the absorptive capacity of the economically developed areas has almost become saturated, while the economically less developed areas need a lot of talents to contribution to their revitalization. The traditional employment concepts of "big city, big business and high income" are not conducive to the common development of society, nor are they conducive to college graduates' own development. The universities, the government and the relevant departments should actively motivate and help college graduates to accept the grassroots employment where they can temper themselves, become talents and integrate their personal ideals closely with the national and social progress. Zhou Ji, Minister of Education, proposed: University graduates' vast employment space lies in the grassroots, where college graduates can exhibit their talents. First, employment at the grassroots level can avoid college graduates' blind search for work so that their expectation will become more rational to achieve the optimal allocation of resources. Second, at the grassroots level, university graduates can hone their will and become talents through hard living and working exercises. They can also develop the spirit to bear hardships and stand hard work, improve their comprehensive quality and grow to become socialist successors with the ability and courage. Third, the grassroots offer a broad space for economic development for college graduates to explore. University graduates can start their own businesses and give full play to their talents and promote the local economic growth while creating more jobs for the employment of university graduates. A survey on employment at the grassroots level reveals that $17.78 \%$ of the graduates are reluctant to go to work at the grassroots level on the grounds of poor work environment, low remunerations, etc. Faced with this situation, the relevant institutions should take measures to encourage university graduates to work at the grassroots level. First, they should strengthen the publicity guidance to encourage university graduates to work at the grassroots level and make them realize the vast space to for their development. Second, they should fully implement the relevant national laws and regulations on employment without taking the route of formalism. The local governments can make use of policy advantage based on their local conditions to attract talents, avoid destabilizing factors brought about by policy changes, improve the employment situation of university graduates, and ensure long-term and stable work for college graduates. Third, they should establish and improve the relevant supporting incentive systems, such as tax relief, micro-credit, social security subsidy, etc. to attract college graduates to the grassroots employment. Fourth, they should enhance the service functions of the government, give full consideration to college graduates and practice the concept of the people-oriented and service-oriented government.

\section{$B$. Building an employment market cultivation mechanism} As an old saying goes, "Knowledge starts with practice." 
It is the most direct, the most efficient and the most scientific means to build and improve the job market training mechanism to enable university students to become the talents needed by society. The practice is an important method for college students to fully understand society and improve their professionalism. Through practice, the job market should open up a broad road for college graduates who are coming out of school and into society. Just as another old saying goes, "Reading ten thousand books is not as effective as traveling one thousand miles." After acquiring professional knowledge in a systematic manner, university graduates need to test their knowledge with practice, combine theory with practice, improve their practical ability, enhance their employability and competitiveness, master the ability to keep up with the times, and forge themselves into talents who can bear hardship and stand hard work, and have high overall quality to be vied by society. The process of practice will strengthen their career training awareness, make scientific and rational and personalized career designs, and avoid the waste of resources caused by blind employment applications. In the process of building a market cultivation mechanism to organize university graduates' practice, the market should pay attention to the following aspects: First, in the process of organizing practice, the market should provide college graduates with the necessary safeguards, such as personal safety, practice expenses, wages and benefits, exit mechanism, etc., all in need of detailed provisions by the market mechanism to provide college graduates with a good practice environment. Second, the practice should be society-oriented and keeping pace with the times. The market should pay close attention to the trend of social development and adjust the direction of personnel training based on demands so that the practice is of more practical efficiency. Third, the market should establish and improve channels for human resources information exchanges, and build a set of comprehensive and long-term employment information networks, so that university graduates and employers can fully understand each other and conduct timely and effective information communication. Meanwhile, we should strengthen the financial input to ensure that the human resources market plays an effective long-term functional role. We should also set up a human resources market supervision system, increase the intensity of the management of the information on employment market, appropriately encourage social capitals to invest in human resource service sectors, and actively mobilize all social forces to establish improved market channels of communication.

\section{Improving the employment guidance mechanism}

Capriciousness is a widespread psychological phenomenon among college graduates at present. A comprehensive employment guidance mechanism is of important significance in enabling university graduates to scientifically and rationally position themselves. Even after years' higher education, university graduates are still short of a rational understanding of society and themselves. There exists blind self-confidence, and even some extremes. They do not have a scientific and rational positioning for themselves. Universities as cradles of talents serve as a valuable pool of human resources in society as a whole. They should speed up the building of a modern career guidance system to enable university graduates to fully understand themselves, tap their own potential and find their own positions in society. First, colleges and universities should increase their emphasis on the employment guidance course and include it in the important day-to-day work. They should organize specialized highcaliber faculty teams to provide graduates with career guidance. They should regularly assess the teachers' teaching achievements and made efforts to solidify the theoretical foundations for university graduates' employment. Second, the contents of the universities' course of employment guidance should advance with the times. The teachers should interpret the employment situations including human resources supply structure, status quo of the economic system, economic trend, etc. and make scientific predictions of the profiles of talent demands in the future in combination with the employment outlines over the recent years, so that university students can promptly learn about the employment situation and make selfadjustment as soon as possible. Finally, efforts should be made to do away with the traditional concept of college graduates on employment and encourage them to work at the grassroots level or in remote areas in west China.

\section{D . Improving an intersectional coordination mechanism}

There is some historical inevitability in the difficulty and complexity of the university graduates' employment in China, and this characteristic dictates that China's promotion of employment of university graduates is a long-term and systematic project in need of intersectoral coordination, harmonization and full cooperation of all the institutions related to the promotion of employment of university graduates. Relevant institutions, while clarifying their own responsibilities and striving to fulfill their responsibilities, should also strengthen cooperation, organize professionals in the various departments to form a professional team to promote the employment of university graduates, increase the intensity of the student information resource exchange, strengthen the awareness of joint governance of the difficulty in university graduates' employment, improve the level of coordination and management, and make it a working mechanism arrangements that will continue to be effectively implemented for a long time. In the process of professional coordination, the good practice model of the government-led employment orientation and stable collaboration relationships among schools, the market and employers should be established. While fulfilling the government's function of public administration, we should strive to form a good model of combined practice and employment, achieve a win-win situation for both the university and the business, and comprehensively improve the level of employment of university graduates. 


\section{References}

[1] Wu Jiang, Establishing a Long-term Mechanism to Crack the Conundrum of University Graduates' Employment. Journal of Human Resources of China, 2009-2010-3-13

[2] Li Guoming, Zhang Wenhai, Zhao Xiangling, Responsibility and Mission of Universities and Colleges for Building a Long-term Mechanism for College Graduates' Employment. Education and Vocation Journal, 2011,8
[3] Liu Qingtang, Interpretation of the "Employment Promotion Law". Journal of Chongqing Institute of Technology, 2008,4

[4] Zheng Yuhe, Building a Long-term Mechanism for University Graduates' Employment from a Legal Perspective. Journal of Xianning College, 2009

[5] Report on Education and Human Resources of China [EB/OL]. Http://www.china.com.cn/chinese 